\title{
Comparison of perioperative outcomes following open versus minimally invasive transforaminal lumbar interbody fusion in obese patients
}

\author{
Darryl Lau, M.D., ${ }^{2}$ Adam Khan, B.A., ${ }^{1}$ Samuel W. Terman, B.S., ${ }^{1}$ Timothy Yee, B.S., ${ }^{1}$ \\ Frank La Marca, M.D., ${ }^{2}$ and Paul Park, M.D. ${ }^{2}$ \\ ${ }^{1}$ University of Michigan Medical School and ${ }^{2}$ Department of Neurosurgery, University of Michigan, \\ Ann Arbor, Michigan
}

Object. Minimally invasive (MI) transforaminal lumbar interbody fusion (TLIF) has proven to be effective in the treatment of spondylolisthesis and degenerative disc disease (DDD). Compared with the traditional open TLIF, the MI procedure has been associated with less blood loss, less postoperative pain, and a shorter hospital stay. However, it is uncertain whether the advantages of an MI TLIF also apply specifically to obese patients. This study was dedicated to evaluating whether obese patients reap the perioperative benefits similar to those seen in patients with normal body mass index (BMI) when undergoing MI TLIF.

Methods. Obese patients - that is, those with a BMI of at least $30 \mathrm{~kg} / \mathrm{m}^{2}$ - who had undergone single-level TLIF were retrospectively identified and categorized according to BMI: Class I obesity, BMI $30.0-34.9 \mathrm{~kg} / \mathrm{m}^{2}$; Class II obesity, BMI $35.0-39.9 \mathrm{~kg} / \mathrm{m}^{2}$; or Class III obesity, BMI $\geq 40.0 \mathrm{~kg} / \mathrm{m}^{2}$. In each obesity class, patients were stratified by TLIF approach, that is, open versus MI. Perioperative outcomes, including intraoperative estimated blood loss (EBL), complications (overall, intraoperative, and 30-day postoperative), and hospital length of stay (LOS), were compared. The chi-square test, Fisher exact test, or 2-tailed Student t-test were used when appropriate.

Results. One hundred twenty-seven patients were included in the final analysis; 49 underwent open TLIF and 78 underwent MI TLIF. Sixty-one patients had Class I obesity (23 open and 38 MI TLIF); 45 patients, Class II (19 open and $26 \mathrm{MI}$ ); and 21 patients, Class III (7 open and $14 \mathrm{MI}$ ). Overall, mean EBL was $397.2 \mathrm{ml}$ and mean hospital LOS was 3.7 days. Minimally invasive TLIF was associated with significantly less EBL and a shorter hospital stay than open TLIF when all patients were evaluated as a single cohort and within individual obesity classes. Overall, the complication rate was $18.1 \%$. Minimally invasive TLIF was associated with a significantly lower total complication rate $(11.5 \%$ MI vs $28.6 \%$ open) and intraoperative complication rate (3.8\% MI vs $16.3 \%$ open) as compared with open TLIF. When stratified by obesity class, MI TLIF was still associated with lower rates of total and intraoperative complications. This effect was most profound and statistically significant in patients with Class III obesity $(42.9 \%$ open vs $7.1 \% \mathrm{MI})$.

Conclusions. Minimally invasive TLIF offers obese patients perioperative benefits similar to those seen in patients with normal BMI who undergo the same procedure. These benefits include less EBL, a shorter hospital stay, and potentially fewer complications compared with open TLIF. Additional large retrospective studies and randomized prospective studies are needed to verify these findings.

(http://thejns.org/doi/abs/10.3171/2013.5.FOCUS13154)

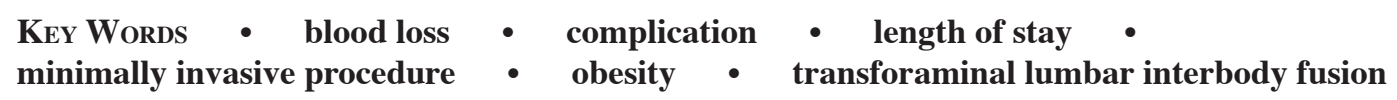

$\mathrm{T}$ HE prevalence of severe obesity is steadily rising, and the proper surgical management of a population with this condition will continue to be an increasingly important issue. ${ }^{9}$ Obesity is a well-known risk factor for a multitude of diseases, such as diabetes mellitus, ${ }^{10}$ hypertension, ${ }^{21}$ osteoarthritis, ${ }^{8}$ and even certain types of cancers. ${ }^{2}$ In addition to the increased risk for medical comorbidities there is, according to a growing body of literature, a higher risk for perioperative complications..$^{1,6,16,18,22,28}$

\footnotetext{
Abbreviations used in this paper: $\mathrm{BMI}=$ body mass index; DDD $=$ degenerative disc disease; $\mathrm{EBL}=$ estimated blood loss; $\mathrm{LOS}=$ length of stay; $\mathrm{MI}=$ minimally invasive; TLIF = transforaminal lumbar interbody fusion.
}

Specifically, obese patients have a greater risk for wound infections ${ }^{6,18}$ complications associated with their obesityrelated comorbidities ${ }^{28}$ deep vein thrombosis, ${ }^{1}$ and pulmonary embolus. ${ }^{1}$ Moreover, there are higher readmission rates due to postoperative complications in obese patients. ${ }^{1}$ Therefore, not surprisingly, obese patients who undergo traditional open lumbar spine surgery also have an increased risk for a variety of perioperative complications, including reoperation, as compared with patients with a BMI within the normal range. $11,13,26,30,33,34$

Despite their higher risk for complications, obese patients still exhibit good long-term outcomes (comparable to those in patients with normal BMI) in terms of symptomatic relief and disease treatment when they undergo ei- 


\section{Lau et al.}

ther open or MI surgery for the treatment of degenerative diseases of the lumbar spine. ${ }^{5,17}$ One of the most common surgical techniques using an MI approach is TLIF for the treatment of spondylolisthesis and DDD. ${ }^{7}$ The advantages of MI TLIF are less postoperative pain, less intraoperative blood loss, and shorter hospital stays while providing long-term outcomes similar to those for open TLIF. 4,15,27 However, there remains a paucity of studies assessing whether these perioperative benefits also apply to obese patients; most studies evaluating the use of MI TLIF have incorporated patients with normal BMI. In the present study, we determined whether obese patients undergoing MI or open TLIF reap similar perioperative benefits. We directly compared intraoperative EBL, complication rate, and duration of hospital stay for open and MI TLIF in separate cohorts of patients with Class I, Class II, and Class III obesity.

\section{Methods}

Approval from the University of Michigan Institutional Review Board was obtained prior to performing this study and reviewing the electronic medical records.

\section{Patient Population}

Patients who had undergone open or MI TLIF performed by one of two neurosurgeons (P.P. or F.L.M.) between 2006 and 2012 were retrospectively identified through the use of electronic medical records. From those initially identified were excluded those patients with the following characteristics: age $<18$ years, BMI $<30.0 \mathrm{~kg} /$ $\mathrm{m}^{2}$, and TLIF of more than 1 level. Patients who had undergone additional spinal instrumentation and posterior fusion beyond 1 vertebra above and below the site of TLIF were then excluded from our analysis to allow a more homogeneous cohort. This resulted in a cohort of obese $\left(\mathrm{BMI} \geq 30.0 \mathrm{~kg} / \mathrm{m}^{2}\right)$ adults who had undergone single-level TLIF. Indications for surgery were pain unresponsive to nonoperative management, neurological deficit, and/or spinal instability (Fig. 1). The MI TLIF technique used in these patients has been described in the literature. ${ }^{23}$

\section{Data Collection}

Data regarding patient demographics, including age at the time of surgery (in years), sex, and BMI (in $\mathrm{kg} / \mathrm{m}^{2}$ ), were recorded. Body mass index was calculated utilizing the following standard formula: weight in $\mathrm{kg} / \mathrm{h}$ eight in square meters. The presence of comorbidities and the patient's smoking status were also noted. Comorbidities included hypertension, coronary artery disease (or history of myocardial infarct), diabetes mellitus, kidney disease, and anemia. Kidney disease was considered to be present if patients had a preoperative creatinine value $>1.3 \mathrm{mg} / \mathrm{dl}$ in men and $>1.1 \mathrm{mg} / \mathrm{dl}$ in women. Anemia was defined as a preoperative hemoglobin value $<13.5 \mathrm{~g} / \mathrm{dl}$ in men and $<$ $12.0 \mathrm{~g} / \mathrm{dl}$ in women. Smoking status was categorized into 3 groups: never (patients who never smoked), past smokers (patients who quit at least 1 year prior to surgery), and current smokers. Diagnoses indicated for surgery included spondylolisthesis, DDD alone (without other associated
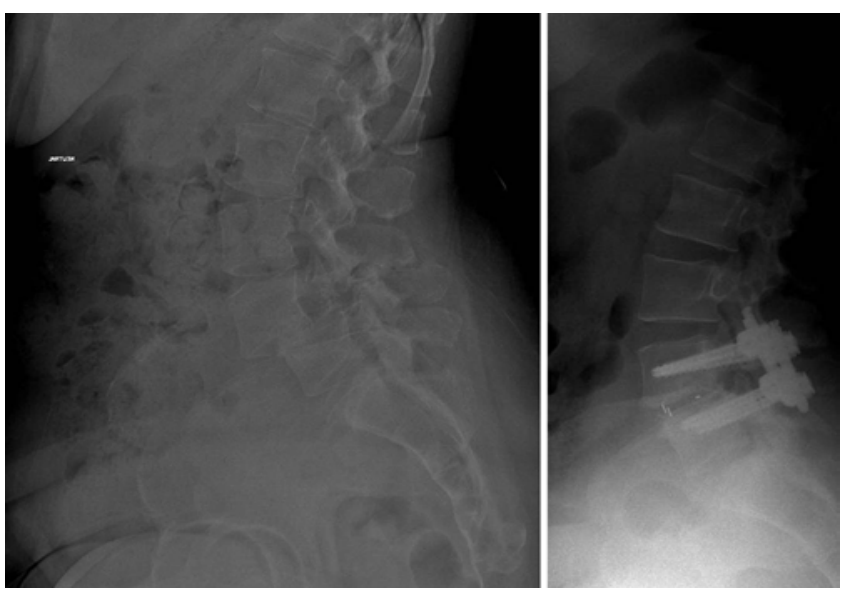

FIG. 1. Left: Lateral radiograph obtained in an obese woman with symptomatic L4-5 spondylolisthesis. Right: Postoperative lateral radiograph obtained after MI TLIF in the same patient, showing instrumentation and interbody cage at L4-5.

pathology), DDD with stenosis, DDD with deformity, and DDD with disc herniation. The lumbar level in which a TLIF was performed was also noted.

Primary outcomes of interest were intraoperative EBL (recorded in $\mathrm{ml}$ ), complication (total, intraoperative, and 30-day postoperative), and length of hospital stay. Total, or overall, complication rate was computed by totaling the number of patients who experienced at least 1 intraoperative and/or postoperative complication. Intraoperative and postoperative complications were recorded separately as well. A postoperative complication was defined as any unforeseen event related to surgery that required additional medical and/or surgical intervention up to 30 days following the surgery. Length of hospital stay was determined by totaling the number of days the patient was hospitalized, beginning on the date of surgery and ending on the date of hospital discharge.

\section{Statistical Analysis}

Patients who met the study inclusion criteria were first categorized into 3 groups based on the WHO BMI classification system: Class I obesity, BMI $30.0-34.9 \mathrm{~kg} / \mathrm{m}^{2}$; Class II obesity, BMI $35.0-39.9 \mathrm{~kg} / \mathrm{m}^{2}$; and Class III obesity, $\mathrm{BMI} \geq 40 \mathrm{~kg} / \mathrm{m}^{2}$. Among each obesity class, patients were subsequently categorized based on whether they had undergone an open or MI TLIF. For each of the 3 obesity classes, descriptive and statistical comparisons of demographics, comorbidities, and diagnoses for the open and MI groups were performed. Comparisons of EBL, total complication rate, intraoperative complications, 30-day postoperative complications, and length of hospital stay were then performed. For categorical outcomes (complications) with a cumulative sample size of at least 50 patients (Class I obesity), the chi-square test was used, and for sample sizes less than 50 patients (Class II and III obesity), the Fisher exact test was applied. For continuous variables (EBL and LOS), a 2-tailed Student t-test was used. A p $<0.05$ was considered significant in this study. All statistical analyses were performed using SAS software, version 9.2 (SAS Institute, Inc.). 


\section{Perioperative outcomes of minimally invasive TLIF and obesity}

\section{Results}

Five hundred ninety-nine patients who had undergone TLIF were identified. Among this initial cohort, 127 patients met the study's a priori criteria of adults with a BMI of at least 30.0 and who had undergone a single-level TLIF. Sixty-one patients had Class I obesity (mean BMI $32.0 \mathrm{~kg} / \mathrm{m}^{2}$ ); 45 patients, Class II obesity (mean BMI 37.0 $\mathrm{kg} / \mathrm{m}^{2}$ ); and 21 patients, Class III obesity (mean BMI 44.4 $\mathrm{kg} / \mathrm{m}^{2}$, range $40.0-53.6 \mathrm{~kg} / \mathrm{m}^{2}$ ). Of the 127 patients, 49 (38.6\%) underwent an open TLIF; and 78 (61.4\%), an MI TLIF. Most patients underwent TLIF for spondylolisthesis (59.1\%). The rest underwent TLIF for DDD alone (18.9\%), DDD with stenosis (15.7\%), DDD with deformity (0.1\%), and DDD with disc herniation (5.5\%). The two most common levels in which TLIF was performed were L4-5 (44.9\%) and L5-S1 (40.2\%). In the overall cohort, mean EBL was $397.2 \mathrm{ml}$, complication was rate was $18.1 \%$, and mean hospital LOS was 3.7 days.

\section{Comparisons of Demographics, Comorbidities, and Diagnoses}

Table 1 features demographics, medical comorbidi- ties, and diagnoses of patients with Class I obesity for the open and MI TLIF groups. Among the 61 patients, 23 (37.7\%) underwent open TLIF and 38 (62.3\%) underwent MI TLIF. The two groups were well matched. There were no significant differences in any of the covariates between the two groups. Table 2 features demographics, medical comorbidities, and diagnoses of patients with Class II obesity for the open and MI TLIF groups. Among the 45 patients, 19 (42.2\%) underwent open TLIF and $26(57.8 \%)$ underwent MI TLIF. The cohorts were well matched, as there were no significant differences among the covariates. Similarly, Table 3 features demographics, medical comorbidities, and diagnoses of 21 patients with Class III obesity for the open and MI TLIF groups. Seven patients (33.3\%) underwent open TLIF, and 14 (66.7\%) underwent MI TLIF. There were no significant differences in covariates between these two groups; both cohorts were well matched.

\section{Intraoperative Blood Loss}

Table 4 features intraoperative EBL among patients who underwent open or MI TLIF. Overall mean EBL was

TABLE 1: Baseline characteristics of patients with Class I obesity who underwent open or MI TLIF procedures*

\begin{tabular}{|c|c|c|c|c|}
\hline \multirow[b]{2}{*}{ Parameter } & \multicolumn{3}{|c|}{ No. (\%) } & \multirow[b]{2}{*}{$\mathrm{p}$ Value } \\
\hline & Total & Open TLIF & MI TLIF & \\
\hline no. of patients & 61 & 23 & 38 & \\
\hline mean $\mathrm{BMl}$ in $\mathrm{kg} / \mathrm{m}^{2}$ & $32.0 \pm 1.4$ & $32.3 \pm 1.4$ & $31.8 \pm 1.4$ & 0.860 \\
\hline mean age in yrs & $53.1 \pm 13.2$ & $54.1 \pm 14.1$ & $52.5 \pm 12.8$ & 0.593 \\
\hline male sex & $31(50.8)$ & $12(52.2)$ & $19(50.0)$ & 0.869 \\
\hline hypertension & $29(47.5)$ & $11(47.8)$ & $18(47.4)$ & 0.972 \\
\hline coronary artery disease & $5(8.2)$ & $3(13.0)$ & $2(5.3)$ & 0.283 \\
\hline diabetes mellitus & $14(23.0)$ & $7(30.4)$ & $7(18.4)$ & 0.280 \\
\hline kidney disease† & $4(6.6)$ & $3(13.0)$ & $1(2.6)$ & 0.283 \\
\hline anemiał & $4(6.6)$ & $3(13.0)$ & $1(2.6)$ & 0.111 \\
\hline smoking status & & & & 0.406 \\
\hline never & $34(55.7)$ & $15(65.2)$ & $19(50.0)$ & \\
\hline past & $14(23.0)$ & $5(21.7)$ & $9(23.7)$ & \\
\hline current & $13(21.3)$ & $3(13.0)$ & $10(26.3)$ & \\
\hline diagnosis & & & & 0.222 \\
\hline spondylolisthesis & $35(57.4)$ & $11(47.8)$ & $24(63.2)$ & \\
\hline DDD alone & $13(21.3)$ & $8(34.8)$ & $5(13.2)$ & \\
\hline DDD w/ stenosis & 8 (13.1) & $3(13.0)$ & $5(13.2)$ & \\
\hline DDD w/ deformity & $0(0.0)$ & $0(0.0)$ & $0(0.0)$ & \\
\hline DDD w/ disc herniation & $5(8.2)$ & $1(4.3)$ & $4(10.5)$ & \\
\hline level of surgery & & & & 0.152 \\
\hline L1-2 & $1(1.6)$ & $1(4.3)$ & $0(0.0)$ & \\
\hline L2-3 & $2(3.3)$ & $0(0.0)$ & $2(5.3)$ & \\
\hline L3-4 & $7(11.5)$ & $5(21.7)$ & $2(5.3)$ & \\
\hline L4-5 & $26(42.6)$ & $9(39.1)$ & $17(44.7)$ & \\
\hline L5-S1 & $25(41.0)$ & $8(34.8)$ & $17(44.7)$ & \\
\hline
\end{tabular}

* Values expressed as means \pm standard deviations, unless indicated otherwise.

$\dagger$ High creatinine was defined as a preoperative creatinine value $>1.3 \mathrm{mg} / \mathrm{dl}$ in men and $>1.1 \mathrm{mg} / \mathrm{dl}$ in women.

$\ddagger$ Anemia was defined as a preoperative hemoglobin value $<13.5 \mathrm{~g} / \mathrm{dl}$ in men and $<12.0 \mathrm{~g} / \mathrm{dl}$ in women. 
D. Lau et al.

TABLE 2: Baseline characteristics of patients with Class II obesity who underwent open or MI TLIF procedures

\begin{tabular}{|c|c|c|c|c|}
\hline \multirow[b]{2}{*}{ Parameter } & \multicolumn{3}{|c|}{ №. $(\%)$} & \multirow[b]{2}{*}{$p$ Value } \\
\hline & Total & Open TLIF & MI TLIF & \\
\hline no. of patients & 45 & 19 & 26 & \\
\hline mean $\mathrm{BMl}$ in $\mathrm{kg} / \mathrm{m}^{2}$ & $37.0 \pm 1.4$ & $37.2 \pm 1.5$ & $36.9 \pm 1.4$ & 0.750 \\
\hline mean age in yrs & $53.4 \pm 13.4$ & $57.4 \pm 12.6$ & $50.5 \pm 13.4$ & 0.792 \\
\hline male sex & $20(44.4)$ & $8(42.1)$ & $12(46.2)$ & 0.787 \\
\hline hypertension & $29(64.4)$ & $12(63.2)$ & $17(65.4)$ & 0.878 \\
\hline coronary artery disease & $3(6.7)$ & $1(5.3)$ & $2(7.7)$ & 0.747 \\
\hline diabetes mellitus & $9(20.0)$ & $4(21.1)$ & $5(19.2)$ & 0.880 \\
\hline kidney disease & $4(8.9)$ & $2(10.5)$ & $2(7.7)$ & 0.741 \\
\hline anemia & $7(15.6)$ & $5(26.3)$ & $2(7.7)$ & 0.089 \\
\hline smoking status & & & & 0.674 \\
\hline none & $25(55.6)$ & $12(63.2)$ & $13(50.0)$ & \\
\hline past & $9(20.0)$ & $3(15.8)$ & $6(23.1)$ & \\
\hline current & $11(24.4)$ & $4(21.1)$ & $7(26.9)$ & \\
\hline diagnosis & & & & 0.214 \\
\hline spondylolisthesis & $23(51.1)$ & $8(42.1)$ & $15(57.7)$ & \\
\hline DDD alone & $9(20.0)$ & $315.8)$ & $6(23.1)$ & \\
\hline DDD w/ stenosis & $12(26.7)$ & $8(42.1)$ & $4(15.4)$ & \\
\hline DDD w/ deformity & $0(0.0)$ & $0(0.0)$ & $0(0.0)$ & \\
\hline DDD w/ disc herniation & $1(2.2)$ & $0(0.0)$ & $1(3.8)$ & \\
\hline level of surgery & & & & 0.073 \\
\hline L1-2 & $0(0.0)$ & $0(0.0)$ & $0(0.0)$ & \\
\hline L2-3 & $2(4.4)$ & $2(10.5)$ & $0(0.0)$ & \\
\hline L3-4 & $5(11.1)$ & $4(21.1)$ & $1(3.8)$ & \\
\hline L4-5 & $18(40.0)$ & $7(36.8)$ & $11(42.3)$ & \\
\hline L5-S1 & $20(44.4)$ & $6(31.6)$ & $14(53.8)$ & \\
\hline
\end{tabular}

$397.2 \mathrm{ml}$. Among the 127 patients, MI TLIF was associated with significantly lower EBL than open TLIF (168.6 vs $661.0 \mathrm{ml}$, respectively; $\mathrm{p}<0.001)$. Among all 3 obesity classes, MI TLIF was also associated with significantly lower EBL than open TLIF: Class I obesity, $\mathrm{p}<0.001$; Class II obesity, $\mathrm{p}<0.001$; and Class III obesity, $\mathrm{p}=0.040$. In the Class I obesity group, the open TLIF group had a mean EBL of $741.3 \mathrm{ml}$ compared with $141.7 \mathrm{ml}$ in the MI TLIF group. In the Class II obesity group, the open TLIF group had a mean EBL of $596.8 \mathrm{ml}$ and the MI TLIF group had a mean EBL of $153.5 \mathrm{ml}$. In patients with Class III obesity, open and MI TLIF were associated with a mean EBL of 614.3 and $269.6 \mathrm{ml}$, respectively.

\section{Complication Rates for Open and MI TLIF}

Complication rates among patients who underwent open or MI TLIF are shown in Table 5. The total complication rate was $18.1 \%$. Patients who underwent open TLIF had significantly higher rates of complication than those who underwent MI TLIF (28.6\% vs $11.5 \%$, respectively; $\mathrm{p}=0.017)$. In addition, open TLIF was associated with significantly higher rates of intraoperative complication than MI TLIF (16.3\% vs 3.8\%, respectively; $\mathrm{p}=0.015$ ). Postoperative complication rates were similar between the two groups (12.2\% open vs $10.3 \% \mathrm{MI}$; $\mathrm{p}=0.729)$.
On stratification by obesity, open and MI groups showed an analogous trend of higher total and intraoperative complication rates, while postoperative complication rates were similar between the open and MI groups. In the group of patients with Class I obesity, open TLIF was associated with higher overall (30.4\% open vs $13.2 \% \mathrm{MI})$ and intraoperative (21.7\% open vs $5.3 \% \mathrm{MI})$ complication rates than the MI group; this was close to being statistically significant $(\mathrm{p}=0.100$ and $\mathrm{p}=0.050$, respectively). Similarly, in patients with Class II obesity, open TLIF had higher overall $(21.1 \%$ open vs $11.5 \% \mathrm{MI})$ and intraoperative $(5.3 \%$ open vs $0.0 \% \mathrm{MI})$ complication rates than MI TLIF ( $p=0.384$ and $p=0.237$, respectively). In patients with Class III obesity, there was a significant difference in the overall complication rate $(\mathrm{p}=0.049)$. Patients who underwent open TLIF had a complication rate of $42.9 \%-\mathrm{a}$ much higher rate than that of the MI group (7.1\%). While the associations were not statistically significant, patients who underwent open TLIF also had higher intraoperative (28.6\% open vs $7.1 \% \mathrm{MI}, \mathrm{p}=0.186$ ) and postoperative (14.3\% open vs $7.1 \% \mathrm{MI}, \mathrm{p}=0.599)$ complication rates than the MI group.

The complications experienced among the study cohort are specified in Table 6 and stratified based on obesity class and approach to TLIF. Most notably, durotomy requiring repair was the most common intraoperative 
Perioperative outcomes of minimally invasive TLIF and obesity

TABLE 3: Baseline characteristics of patients with Class III obesity who underwent open or MI TLIF procedures

\begin{tabular}{|c|c|c|c|c|}
\hline \multirow[b]{2}{*}{ Parameter } & \multicolumn{3}{|c|}{ №. $(\%)$} & \multirow[b]{2}{*}{ p Value } \\
\hline & Total & Open TLIF & MI TLIF & \\
\hline no. of patients & 21 & 7 & 14 & \\
\hline mean $\mathrm{BMI}$ in $\mathrm{kg} / \mathrm{m}^{2}$ & $44.4 \pm 4.2$ & $46.3 \pm 4.9$ & $43.4 \pm 3.7$ & 0.351 \\
\hline mean age in yrs & $55.5 \pm 12.6$ & $59.4 \pm 12.9$ & $53.5 \pm 3.3$ & 0.848 \\
\hline male sex & $10(47.6)$ & $3(42.9)$ & $7(50.0)$ & 0.757 \\
\hline hypertension & $16(76.2)$ & $5(71.4)$ & $11(78.6)$ & 0.717 \\
\hline coronary artery disease & $2(9.5)$ & $1(14.3)$ & $1(7.1)$ & 0.599 \\
\hline diabetes mellitus & $5(23.8)$ & $3(42.9)$ & $2(14.3)$ & 0.147 \\
\hline kidney disease & $3(14.3)$ & $1(14.3)$ & $2(14.3)$ & 0.999 \\
\hline anemia & $1(4.8)$ & $1(14.3)$ & $0(0.0)$ & 0.147 \\
\hline smoking status & & & & 0.829 \\
\hline none & $15(71.4)$ & $5(71.4)$ & $10(71.4)$ & \\
\hline past & $4(19.0)$ & $1(14.3)$ & $3(21.4)$ & \\
\hline current & $2(9.5)$ & $1(14.3)$ & $1(7.1)$ & \\
\hline diagnosis & & & & 0.734 \\
\hline spondylolisthesis & $17(81.0)$ & $6(85.7)$ & $11(78.6)$ & \\
\hline DDD alone & $2(9.5)$ & $1(14.3)$ & $1(7.1)$ & \\
\hline DDD w/ stenosis & $0(0.0)$ & $0(0.0)$ & $0(0.0)$ & \\
\hline DDD w/ deformity & $1(4.8)$ & $0(0.0)$ & $1(7.1)$ & \\
\hline DDD w/ disc herniation & $1(4.8)$ & $0(0.0)$ & $1(7.1)$ & \\
\hline level of surgery & & & & 0.091 \\
\hline $\mathrm{L} 1-2$ & $0(0.0)$ & $0(0.0)$ & $0(0.0)$ & \\
\hline L2-3 & $0(0.0)$ & $0(0.0)$ & $0(0.0)$ & \\
\hline L3-4 & $2(9.5)$ & $2(28.6)$ & $0(0.0)$ & \\
\hline L4-5 & $13(61.9)$ & $4(57.1)$ & $9(64.3)$ & \\
\hline L5-S1 & $6(28.6)$ & $1(14.3)$ & $5(35.7)$ & \\
\hline
\end{tabular}

complication, and infection was the most common postoperative complication. There was 1 case in which a Kwire was fractured in an L-5 vertebral body during an MI TLIF.

\section{Length of Hospital Stay}

Table 7 compares hospital LOS for patients who underwent open TLIF and those who underwent MI TLIF, stratified by obesity class. The overall mean LOS was 3.7 days, and patients who underwent open TLIF had a significantly longer LOS than patients who underwent MI TLIF (4.7 days vs 3.1 days, respectively; $p<0.001$ ). In fact, this association was also the case when stratified by obesity class. Among patients with Class I and Class II obesity, the open group had a significantly longer LOS than the MI group (Class I: 4.2 days vs 3.0 days, $\mathrm{p}=0.004$; and Class II: 4.7 days vs 3.0 days, $\mathrm{p}=0.002$, respectively). A similar trend was also seen in patients with Class III obesity; the open group stayed in the hospital for 4.6 days and the MI group stayed for 3.6 days, although this association was not statistically significant $(\mathrm{p}=0.345)$.

\section{Discussion}

Transforaminal lumbar interbody fusion is a surgical technique that has proven to be successful in improving symptoms associated with spondylolisthesis and DDD of the lumbar spine. ${ }^{19}$ The procedure has evolved over the past 10 years, with MI approaches becoming increasingly

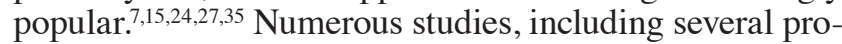
spective ones, indicate that MI TLIF has advantages over open TLIF with regard to perioperative outcomes. $.^{27,31} \mathrm{Spe}-$ cifically, these advantages consist of less intraoperative blood loss, ${ }^{15,27,31}$ fewer intraoperative transfusion requirements, ${ }^{15}$ less postoperative pain, ${ }^{27,31}$ shorter time to am-

TABLE 4: Intraoperative EBL in patients who underwent open or MI TLIF procedures*

\begin{tabular}{lcccc}
\hline \multicolumn{1}{c}{ Group } & Overall & Open TLIF & MI TLIF & $\begin{array}{c}p \\
\text { Value }\end{array}$ \\
\hline $\begin{array}{l}\text { overall } \\
\text { Class I obes- } \\
\quad \text { ity }\end{array}$ & $443.2 \pm 494.6$ & $661.0 \pm 561.3$ & $168.6 \pm 16.2 .1$ & $<0.001$ \\
$\begin{array}{l}\text { Class II obes- } \\
\text { ity }\end{array}$ & $340.7 \pm 356.6$ & $596.8 \pm 415.7$ & $153.5 \pm 114.2$ & $<0.001$ \\
$\begin{array}{l}\text { Class III ob- } \\
\text { esity }\end{array}$ & $384.5 \pm 368.1$ & $614.3 \pm 449.7$ & $269.6 \pm 269.2$ & 0.040 \\
\hline * Values expressed in ml. & & & \\
\hline
\end{tabular}


D. Lau et al.

TABLE 5: Complications in patients who underwent open or MI TLIF procedures

\begin{tabular}{|c|c|c|c|c|}
\hline Group \& Complication & Total & Open TLIF & MI TLIF & $p$ Value \\
\hline \multicolumn{5}{|l|}{ total } \\
\hline no. of patients & 127 & 49 & 78 & \\
\hline overall $^{*}$ & $23(18.1)$ & $14(28.6)$ & $9(11.5)$ & 0.017 \\
\hline intraop & $11(8.7)$ & $8(16.3)$ & $3(3.8)$ & 0.015 \\
\hline postop & $14(11.0)$ & $6(12.2)$ & $8(10.3)$ & 0.729 \\
\hline \multicolumn{5}{|l|}{ Class I obesity } \\
\hline no. of patients & 61 & 23 & 38 & \\
\hline overall $^{*}$ & $12(19.7)$ & $7(30.4)$ & $5(13.2)$ & 0.100 \\
\hline intraop & 7 (11.5) & $5(21.7)$ & $2(5.3)$ & 0.050 \\
\hline postop & $6(9.8)$ & $2(8.7)$ & $4(10.5)$ & 0.816 \\
\hline \multicolumn{5}{|l|}{ Class II obesity } \\
\hline no. of patients & 45 & 19 & 26 & \\
\hline overall ${ }^{*}$ & $7(15.6)$ & $4(21.1)$ & $3(11.5)$ & 0.384 \\
\hline intraop & $1(2.2)$ & $1(5.3)$ & $0(0.0)$ & 0.237 \\
\hline postop & $6(13.3)$ & $3(15.8)$ & $3(11.5)$ & 0.679 \\
\hline \multicolumn{5}{|l|}{ Class III obesity } \\
\hline no. of patients & 21 & 7 & 14 & \\
\hline overall $^{\star}$ & $4(19.0)$ & $3(42.9)$ & $1(7.1)$ & 0.049 \\
\hline intraop & $3(14.3)$ & $2(28.6)$ & $1(7.1)$ & 0.186 \\
\hline postop & $2(9.5)$ & $1(14.3)$ & $1(7.1)$ & 0.599 \\
\hline
\end{tabular}

* Overall complication rate is based on tally of individual patients who had an intraoperative and/or postoperative complication.

bulation, ${ }^{15}$ and shorter length of hospital stay ${ }^{15,27,31}$ while providing similar long-term functional outcomes as open TLIF. ${ }^{15,23}$ The main disadvantages of MI TLIF include additional exposure time to intraoperative radiation, ${ }^{27}$ potential excess cost, ${ }^{25}$ and the surgeon's ability to overcome the learning curve as traditional surgical landmarks can be distorted with the use of a tubular retractor. ${ }^{15,32}$

Minimally invasive TLIF has been applied to the treatment of overweight and obese patients, and prior studies have shown that in such cases the patients obtain benefits equal to those in patients with normal BMI. In a prospective, single-center, nonrandomized control clinical study, Wang et al. ${ }^{35}$ showed that MI TLIF in overweight and obese patients resulted in significantly less operating time, less blood loss, and less postoperative back pain compared with open TLIF; these findings are similar to

TABLE 6: Specific complications in patients who underwent open or MI TLIF, stratified by BMI class and surgical approach* $^{*}$

\begin{tabular}{|c|c|c|}
\hline $\begin{array}{l}\text { Group \& Time of } \\
\text { Complication }\end{array}$ & Open TLIF (no. of cases) & MI TLIF (no. of cases) \\
\hline \multicolumn{3}{|l|}{ Class I obesity } \\
\hline intraop & durotomy w/ primary repair (5) & $\begin{array}{l}\text { durotomy w/ primary repair (1) } \\
\text { fractured K-wire in L-5 vertebral body (1) }\end{array}$ \\
\hline postop & $\begin{array}{l}\text { UTI (1) } \\
\text { valium w/drawal (1) }\end{array}$ & $\begin{array}{l}\text { wound dehiscence (1) } \\
\text { atrial fibrillation w/ rapid ventricular response (1) } \\
\text { UTI (2) }\end{array}$ \\
\hline \multicolumn{3}{|l|}{ Class II obesity } \\
\hline $\begin{array}{l}\text { intraop } \\
\text { postop }\end{array}$ & $\begin{array}{l}\text { durotomy w/ primary repair (1) } \\
\text { development of seroma (1) } \\
\text { reoperation for screw revision (1) } \\
\text { wound infection (1) }\end{array}$ & $\begin{array}{l}\text { tachycardia associated w/ respiratory failure (1) } \\
\text { UTI (1) } \\
\text { lower-extremity DVT (1) }\end{array}$ \\
\hline \multicolumn{3}{|l|}{ Class III obesity } \\
\hline intraop & durotomy withdrawal primary repair (2) & durotomy w/ primary repair (1) \\
\hline postop & reoperation for medially displaced pedicle screw \& DVT (1) & UTI \& pneumonia (1) \\
\hline
\end{tabular}

* DVT = deep vein thrombosis; UTI = urinary tract infection. 


\section{Perioperative outcomes of minimally invasive TLIF and obesity}

TABLE 7: Hospital LOS for patients who underwent open or MI TLIF procedures*

\begin{tabular}{lcccc}
\hline \multicolumn{1}{c}{ Group } & Overall & Open TLIF & MI TLIF & p Value \\
\hline overall & $3.7 \pm 2.0$ & $4.7 \pm 2.1$ & $3.1 \pm 1.7$ & $<0.001$ \\
Class I obesity & $3.6 \pm 2.0$ & $4.2 \pm 2.1$ & $3.0 \pm 2.0$ & 0.004 \\
Class II obesity & $3.8 \pm 1.9$ & $4.7 \pm 2.1$ & $3.0 \pm 1.4$ & 0.002 \\
Class III obesity & $3.9 \pm 1.9$ & $4.6 \pm 2.2$ & $3.6 \pm 1.6$ & 0.345 \\
\hline
\end{tabular}

* Values expressed in days.

those among patients with normal BMI. ${ }^{12}$ In addition, in 2 earlier studies (Park et al. ${ }^{24}$ and Lau et al. ${ }^{17}$ ), we demonstrated that there was no significant difference in the complication rate, ${ }^{17,24}$ intraoperative blood loss, ${ }^{17}$ or length of hospital stay ${ }^{17}$ between obese patients and patients with normal BMI when undergoing MI TLIF. Senker at al. ${ }^{32}$ also found similar results when comparing normal weight, overweight, and obese patients who underwent MI TLIF. These findings suggest that MI TLIF can also provide perioperative benefits to obese patients. However, formulating conclusions on whether MI TLIF can benefit patients of all obesity classes and applying the findings from current studies is difficult because of the heterogeneity of the cohorts and the nonoptimal classification and analysis of obese BMI. In the prospective clinical study by Wang et al., ${ }^{35}$ the authors rightfully defined overweight as $25.0-29.9 \mathrm{~kg} / \mathrm{m}^{2}$ and obesity as $30.0 \mathrm{~kg} / \mathrm{m}^{2}$ and greater. Upon analysis, however, they combined both categories and ended up with a mean BMI of $29.5 \mathrm{~kg} / \mathrm{m}^{2}$ in the MI group and $28.3 \mathrm{~kg} / \mathrm{m}^{2}$ in the open group. Formally, these BMIs correlate with the overweight category rather than the obese category. In addition, only $37 \%$ of patients were obese. Similarly, in one of our own prior studies, overweight patients were combined with obese patients, resulting in a mean BMI of $30.4 \mathrm{~kg} / \mathrm{m}^{2}{ }^{24}$ The study by Lau et al. ${ }^{17}$ had a patient cohort with a mean BMI of $37.4 \mathrm{~kg} / \mathrm{m}^{2}$ that formally met the definition of Class II obesity, but it consisted of a small cohort of 9 patients who underwent MI TLIF.

Therefore, the purpose of the present study was to determine if all classes of obese patients obtained the same perioperative benefits following MI TLIF. In this study, cohort sizes in each obesity class were adequate, and all 3 classes of obesity were well-matched when stratified into open and MI TLIF groups. Our findings suggested that MI TLIF is associated with significantly less EBL and a shorter hospital stay. With regard to complication rates, there is a trend for lower complication rates when patients with Class I and Class II obesity undergo MI TLIF compared with those who undergo open TLIF. In fact, among patients with Class III obesity, MI TLIF was associated with a significantly lower total complication rate than open TLIF, and the difference was quite profound, as the open group experienced about $36 \%$ more complications. Thus, it seems that MI TLIF can offer patients of all obesity classes the same perioperative benefits seen in patients with normal BMI. In addition, MI TLIF may even be associated with a reduction in the complication rate as obesity increases beyond a BMI of $40 \mathrm{~kg} / \mathrm{m}^{2}$.
In obese patients, lower EBL and shorter LOS are most likely attributable to the same proposed mechanisms previously described in patients with normal BMI who undergo MI TLIF: smaller incisions, lower degree of tissue manipulation, and less muscle damage than traditional open approaches. However, it is less intuitive how one can achieve lower intraoperative complication rates with MI than with open TLIF among all 3 obesity classes. All intraoperative complications in the open group were durotomies requiring primary repair. The most likely reason for this finding is random chance or the inherent difficulties experienced when operating on obese patients. In such patients, especially the morbidly obese, it can be physically difficult to achieve adequate exposure given the presence of excess adiposity, muscle, and tissue around the surgical site, and at times, incisions and muscle dissections must be extended. In such circumstances, performing the discectomy and placing the interbody cage during a TLIF can also be more difficult, thus increasing the risk of durotomy. While it is true that with the MI TLIF, more tissue must be traversed with the tubular retractor, obtaining adequate exposure is less challenging as the retractor is inserted through the paraspinal musculature directly over the targeted segment. In this way, MI TLIF may decrease durotomy rates in obese patients.

Patients with Class III obesity who underwent open TLIF had higher intraoperative and postoperative complication rates than those who underwent MI TLIF. In patients with Class III obesity, the combination of both intraoperative and postoperative complications contributed to the finding that the total complication rate was significantly higher in the open TLIF group than in the MI TLIF group. Moreover, the combination of intraoperative and postoperative complications led to an overall complication rate of more than $40 \%$ in the open group. The reasons for the higher rates of postoperative complications that are not seen in Class I and Class II obesity may relate to the inherent medical attributes of patients with Class III obesity. As noted previously, adequate exposure through an open approach can be difficult to achieve in severely obese patients and can lead to increased difficulty in adequately performing the procedure. In particular, in open TLIF cases, obtaining the correct trajectory for pedicle screw placement in the severely obese can be challenging. This was actually well demonstrated in one of the Class III obesity patients who underwent open TLIF; the patient experienced a postoperative complication in the form of reoperation for replacement of a medially placed pedicle screw. This complication might have been avoided with MI percutaneous pedicle screw placement, as trajectory is not as strictly limited by exposure.

Postoperative medical management of patients with Class III obesity is probably different for patients in lower obesity classes. It is reported that approximately $75 \%$ of adults with Class III obesity have at least one comorbid condition, such as high blood pressure or diabetes mellitus. ${ }^{20}$ This statistic conforms to our cohort of Class III obesity patients, which had a very high prevalence of hypertension, coronary artery disease, diabetes, and kidney disease. In addition, the rates of these comorbidities in the Class III obese were higher than those in the Class I and 


\section{Lau et al.}

II obese. Patients with Class III obesity also have additional risk factors that are not seen among Class I and II obese, such as a higher risk for deep vein thrombosis ${ }^{14}$ and a baseline 2-fold increased risk for all-cause mortality as compared with risks in the Class II obese. ${ }^{3}$ Therefore, additional care may be warranted during the postoperative course among these particular patients.

This study has important implications for clinical practice and future research. Obesity should not be considered a contraindication to MI lumbar spine surgery. ${ }^{29}$ Moreover, the results of this study suggest that MI TLIF may result in a decreased complication risk in obese patients, especially those with Class III obesity.

\section{Study Limitations}

To our knowledge, this is the first study in which open and MI TLIF has been compared among the 3 obesity classes. However, there are limitations to the study. The major concern is the intrinsic drawback to a retrospective design, which allows susceptibly to certain biases. In this study, the major bias would be selection bias when deciding which patients should undergo an open or MI approach to TLIF. However, this bias (potential confounder) is probably not as significant, as the open and MI groups were all well matched with regard to demographics, comorbidities, and diagnoses.

\section{Conclusions}

In patients with Class I, II, and III obesity, MI TLIF offers perioperative benefits similar to those experienced by patients with normal BMI. Compared with open TLIF, MI TLIF is associated with significantly less intraoperative EBL and a shorter hospital LOS. Our results also suggest that an MI approach to TLIF in obese patients can lead to lower complication rates, especially for patients with Class III obesity (BMI $\geq 40.0 \mathrm{~kg} / \mathrm{m}^{2}$ ).

\section{Disclosure}

Dr. Park is a consultant for Globus Medical and Medtronic. Dr. La Marca is a consultant for Globus Medical, Lanx, and Biomet, and has received royalties from Stryker and Globus Medical.

Author contributions to the study and manuscript preparation include the following. Conception and design: Park, La Marca. Acquisition of data: all authors. Analysis and interpretation of data: Park, Lau, Khan, Terman, Yee. Drafting the article: Lau, Khan, Terman, Yee. Critically revising the article: Park. Reviewed submitted version of manuscript: all authors. Approved the final version of the manuscript on behalf of all authors: Park. Statistical analysis: Park, Lau. Study supervision: Park, La Marca.

\section{References}

1. Aghi MK, Eskandar EN, Carter BS, Curry WT Jr, Barker FG II: Increased prevalence of obesity and obesity-related postoperative complications in male patients with meningiomas. Neurosurgery 61:754-761, 2007

2. Calle EE, Rodriguez C, Walker-Thurmond K, Thun MJ: Overweight, obesity, and mortality from cancer in a prospectively studied cohort of U.S. adults. N Engl J Med 348:1625-1638, 2003

3. Calle EE, Thun MJ, Petrelli JM, Rodriguez C, Heath CW Jr: Body-mass index and mortality in a prospective cohort of U.S adults. N Engl J Med 341:1097-1105, 1999
4. Dhall SS, Wang MY, Mummaneni PV: Clinical and radiographic comparison of mini-open transforaminal lumbar interbody fusion with open transforaminal lumbar interbody fusion in 42 patients with long-term follow-up. Clinical article. J Neurosurg Spine 9:560-565, 2008

5. Djurasovic M, Bratcher KR, Glassman SD, Dimar JR, Carreon LY: The effect of obesity on clinical outcomes after lumbar fusion. Spine (Phila Pa 1976) 33:1789-1792, 2008

6. Espejo B, Torres A, Valentín M, Bueno B, Andrés A, Praga M, et al: Obesity favors surgical and infectious complications after renal transplantation. Transplant Proc 35:1762-1763, 2003

7. Etame AB, Wang AC, Than KD, Park P: Clinical and radiographic outcomes after minimally invasive transforaminal lumbar interbody fusion. SAS J 4:47-53, 2010

8. Felson DT, Anderson JJ, Naimark A, Walker AM, Meenan RF: Obesity and knee osteoarthritis. The Framingham Study. Ann Intern Med 109:18-24, 1988

9. Freedman DS, Khan LK, Serdula MK, Galuska DA, Dietz WH: Trends and correlates of class 3 obesity in the United States from 1990 through 2000. JAMA 288:1758-1761, 2002

10. Gallagher EJ, LeRoith D, Karnieli E: The metabolic syndrome-from insulin resistance to obesity and diabetes. Endocrinol Metab Clin North Am 37:559-579, vii, 2008

11. Gaudelli C, Thomas K: Obesity and early reoperation rate after elective lumbar spine surgery: a population-based study. Evid Based Spine Care J 3:11-16, 2012

12. Habib A, Smith ZA, Lawton CD, Fessler RG: Minimally invasive transforaminal lumbar interbody fusion: a perspective on current evidence and clinical knowledge. Minim Invasive Surg 2012:657342, 2012

13. Knutsson B, Michaëlsson K, Sandén B: Obesity is associated with inferior results after surgery for lumbar spinal stenosis: a study of 2633 patients from the Swedish spine register. Spine (Phila Pa 1976) 38:435-441, 2013

14. LaMattina JC, Foley DP, Fernandez LA, Pirsch JD, Musat AI, D'Alessandro AM, et al: Complications associated with liver transplantation in the obese recipient. Clin Transplant 26: 910-918, 2012

15. Lau D, Lee JG, Han SJ, Lu DC, Chou D: Complications and perioperative factors associated with learning the technique of minimally invasive transforaminal lumbar interbody fusion (TLIF). J Clin Neurosci 18:624-627, 2011

16. Lau D, Terman SW, Patel R, La Marca F, Park P: Incidence of and risk factors for superior facet violation in minimally invasive versus open pedicle screw placement during transforaminal lumbar interbody fusion: a comparative analysis. Clinical article. J Neurosurg Spine 18:356-361, 2013

17. Lau D, Ziewacz J, Park P: Minimally invasive transforaminal lumbar interbody fusion for spondylolisthesis in patients with significant obesity. J Clin Neurosci 20:80-83, 2013

18. Lynch RJ, Ranney DN, Shijie C, Lee DS, Samala N, Englesbe MJ: Obesity, surgical site infection, and outcome following renal transplantation. Ann Surg 250:1014-1020, 2009

19. Mura PP, Costaglioli M, Piredda M, Caboni S, Casula S: TLIF for symptomatic disc degeneration: a retrospective study of 100 patients. Eur Spine J 20 Suppl 1:S57-S60, 2011

20. Must A, Spadano J, Coakley EH, Field AE, Colditz G, Dietz WH: The disease burden associated with overweight and obesity. JAMA 282:1523-1529, 1999

21. Nguyen T, Lau DC: The obesity epidemic and its impact on hypertension. Can J Cardiol 28:326-333, 2012

22. Noun R, Riachy E, Ghorra C, Yazbeck T, Tohme C, Abboud B, et al: The impact of obesity on surgical outcome after pancreaticoduodenectomy. JOP 9:468-476, 2008

23. Park P, Foley KT: Minimally invasive transforaminal lumbar interbody fusion with reduction of spondylolisthesis: technique and outcomes after a minimum of 2 years' follow-up. Neurosurg Focus 25(2):E16, 2008

24. Park P, Upadhyaya C, Garton HJ, Foley KT: The impact of 


\section{Perioperative outcomes of minimally invasive TLIF and obesity}

minimally invasive spine surgery on perioperative complications in overweight or obese patients. Neurosurgery 62:693699,2008

25. Parker SL, Mendenhall SK, Shau DN, Zuckerman SL, Godil SS, Cheng JS, et al: Minimally invasive versus open transforaminal lumbar interbody fusion (TLIF) for degenerative spondylolisthesis: comparative effectiveness and cost-utility analysis. World Neurosurg [epub ahead of print], 2013

26. Patel N, Bagan B, Vadera S, Maltenfort MG, Deutsch H, Vaccaro AR, et al: Obesity and spine surgery: relation to perioperative complications. J Neurosurg Spine 6:291-297, 2007

27. Peng CW, Yue WM, Poh SY, Yeo W, Tan SB: Clinical and radiological outcomes of minimally invasive versus open transforaminal lumbar interbody fusion. Spine (Phila Pa 1976) 34: 1385-1389, 2009

28. Rogde AJ, Gudbrandsdottir G, Hjelle KM, Sand KE, Bostad $\mathrm{L}$, Beisland C: Obesity is associated with an improved cancerspecific survival, but an increased rate of postoperative complications after surgery for renal cell carcinoma. Scand J Urol Nephrol 46:348-357, 2012

29. Rosen DS, Ferguson SD, Ogden AT, Huo D, Fessler RG: Obesity and self-reported outcome after minimally invasive lumbar spinal fusion surgery. Neurosurgery 63:956-960, 2008

30. Sami Walid M, Zaytseva NV: The impact of chronic obstructive pulmonary disease and obesity on length of stay and cost of spine surgery. Indian J Orthop 44:424-427, 2010

31. Schizas C, Tzinieris N, Tsiridis E, Kosmopoulos V: Minimally invasive versus open transforaminal lumbar interbody fusion: evaluating initial experience. Int Orthop 33:1683-1688, 2009
32. Senker W, Meznik C, Avian A, Berghold A: Perioperative morbidity and complications in minimal access surgery techniques in obese patients with degenerative lumbar disease. Eur Spine J 20:1182-1187, 2011

33. Vaidya R, Carp J, Bartol S, Ouellette N, Lee S, Sethi A: Lumbar spine fusion in obese and morbidly obese patients. Spine (Phila Pa 1976) 34:495-500, 2009

34. Walid MS, Robinson JS III, Robinson ER, Brannick BB, Ajjan M, Robinson JS Jr: Comparison of outpatient and inpatient spine surgery patients with regards to obesity, comorbidities and readmission for infection. J Clin Neurosci 17:1497-1498, 2010

35. Wang J, Zhou Y, Feng Zhang Z, Qing Li C, Jie Zheng W, Liu $\mathrm{J}$ : Comparison of clinical outcome in overweight or obese patients after minimally invasive versus open transforaminal lumbar interbody fusion. J Spinal Disord Tech [epub ahead of print], 2012

Manuscript submitted April 12, 2013.

Accepted May 28, 2013.

Please include this information when citing this paper: DOI: 10.3171/2013.5.FOCUS13154.

Address correspondence to: Paul Park, M.D., Department of Neurosurgery, University of Michigan, 1500 E. Medical Center Dr., Room 3552 TC, Ann Arbor, MI 48109-5338. email: ppark@umich. edu. 